\title{
PODER, REDES E IDEOLOGIA NO CAMPO DO DESENVOLVIMENTO
}

GUSTAVO LINS RibEIRO

\section{RESUMO}

Neste artigo, desenvolvimento é visto como um campo de poder formado por muitas redes e instituições. A noção de "consorciação" é apresentada para explicar as articulações entre os diferentes atores do campo do desenvolvimento. Além disso, desenvolvimento é tratado como uma ideologia e utopia, como um discurso atravessado por categorias culturais ocidentais e vinculado à expansão econômica capitalista. A discussão sobre os "dramas desenvolvimentistas" permite identificar dois tipos de sujeitos gerados por encontros desiguais entre atores locais e outsiders.

PALAVRAS-CHAVE: desenvolvimento; campos de poder; expansão econômica.

\section{SUMMARY}

In this article I see development as a power field made up of many networks and institutions. I present the notion of "consortiation" to explain the articulations among the different actors of the development field. Furthermore, development is approached as an ideology and utopia, a discourse traversed by cultural western categories and linked to the economic expansion of capitalism. The discussion on "developmentalist dramas" allows for the identification of two types of subjects generated by the unequal encounters between local actors and outsiders.

KEYWORDS: development; power fields; economic expansion.

[1] Compartilho da opinião de Rist segundo a qual a crítica precisa ser "entendida no seu sentido kantiano de exame livre e público ao invés de no seu sentido usual de julgamento desfavorável" (Rist, Gilbert. The history of development:from western origins to global faith. London, New York: Zed Books, 1997, p.30).

[2] Durkheim, Émile.Lasformaselementales de la vida religiosa. Buenos Aires: Schapire, 1968.
Há sempre crises conceituais se desdobrando internamente ao campo do desenvolvimento e da cooperação técnica, promovendo momentos profícuos para realizar mudanças nas formações discursivas relacionadas. Se quisermos ir além de teorias e conceitos reciclados, novas formulações precisam se basear em uma crítica do campo maior das atividades de desenvolvimento‥Após várias décadas de proeminência do discurso sobre desenvolvimento, não há mais lugar para inocência. Inspirado pelo conhecido argumento de Durkheim ${ }^{2}$ segundo o qual religião é a sociedade adorando a si própria, entendo desenvolvimento como a expansão econômica adorando a si mesma. Isso significa que precisamos conhecer o sistema de crença que subjaz a essa devoção assim como as características do campo de poder que a sustenta. 
Poder, uma noção central deste texto, tem muitas definições. Minha própria concepção baseia-se na combinação de três fontes diferentes. Para Richard Adams 3 , poder é o controle que um coletivo possui sobre o ambiente de outro coletivo. Das diversas visões de Max Weber, reterei aquela do poder como a capacidade de incitar pessoas a fazerem o que não querem. Já a noção de poder estrutural, de Eric Wolf4, enfatiza a capacidade que forças e relações históricas especialmente aquelas que definem acesso ao trabalho social - têm de criar e organizar cenários que constrangem as possibilidades de ação das pessoas e de especificar a direção e distribuição de fluxos de energia. Poder, assim, refere-se à capacidade (a) de ser sujeito do seu próprio ambiente, de ser capaz de controlar seu próprio destino, quer dizer, de controlar o curso da ação ou dos eventos que manterão a vida como está ou a modificarão; ou (b) de impedir as pessoas de se tornarem atores "empoderados". Já que o desenvolvimento sempre implica transformação 5 e tipicamente ocorre por meio de encontros entre insiders e outsiders localizados em posições de poder diferentes, as iniciativas de desenvolvimento estão ancoradas e atravessadas por situações em que desigualdades de poder abundam. A dificuldade de realizar mudanças internamente à chamada "comunidade de desenvolvimento" está intimamente relacionada ao fato de a mesma ser um campo de poder.

\section{DESENVOLVIMENTO COMO CAMPO DE PODER}

Bourdieu ${ }^{6}$ define um campo como uma série de relações e interrelações baseada em valores específicos e práticas que operam em dados contextos. Um campo é heterogêneo por definição;eleéfeito de diferentes atores, instituições, discursos e forças em tensão. Dentro de um campo, tudo faz sentido em termos relacionais por meio de oposições e distinções. Estratégias de cooperação ou conflito entre atores determinam se uma doutrina particular é hegemônica, não obstante seus sucessos ou falhas7.

O campo do desenvolvimento é constituído por atores que representam vários segmentos de populações locais (elites locais elíderes de movimentos sociais, por exemplo); empresários privados, funcionários e políticos em todos os níveis de governo; pessoal de corporações nacionais, internacionais e transnacionais (diferentes tipos de empreiteiros e consultores, por exemplo); e pessoal de organizações internacionais de desenvolvimento (funcionários de agências multilaterais e bancos regionais, por exemplo). As instituições são parte importante desse campo; elas incluem vários tipos de organizações governamentais, organizações não-governamentais, igrejas, sindicatos, agências multilaterais, entidades industriais e corporações financeiras.
[3] Adams, Richard.Thesecondsowing: powerand secondary development in $\mathrm{La}$ tin America. San Francisco: Chandler Publishing Company, 1967

[4] Wolf, Eric. Envisioning power: ideologies of dominance and crisis. Berkeley: University of California Press, 1999.

[5] Berman, Marshall.Tudoqueésólido desmancha no ar. São Paulo: Cia. das Letras, 1987.

[6] Bourdieu, Pierre. Questions de sociologie. Paris: Editions de Minuit, 1986.

[7] Perrot, Marie-Dominique e outros. La mythologie programmée: l'économie des croyances dans la société moderne. Paris: PUF, 1992, pp. 202-204. 
[8] Barros, Flávia Lessa de. "Ambientalismo, globalização e novos atores sociais." Sociedade e Estado, vol. $\mathrm{XI}, \mathrm{n}^{\mathrm{Q}}$ 1, 1996, pp. 121-137.
[9] Minha opção por enfocar os projetos de grande escala é de ordem metodológica. Estou seguindo a idéia de Alfred Kroeber ("On human nature". Southwestern Journal of Anthropology, $\left.\mathrm{n}^{\mathrm{2}} 11,1955, \mathrm{pp} .195-204\right) \mathrm{de}$ que é preciso estudar "as mais extremas expressões" de uma série de fenômenos para melhor entendê-los. Os engenheiros militares primeiro $e$ depois os engenheiros civis tiveram um grande papel na estruturação desse campo, a partir do século XVIII (Ribeiro, Gustavo Lins. "Cuanto más grande mejor? proyectos de gran escala: una forma de producción vinculada a la expansión de sistemas económicos". Desarrollo Económico, $\mathrm{n}^{\mathrm{Q}}$ 105, 1987, pp.3-27).

[10] Ibidem.
A estrutura e a dinâmica de cada campo de desenvolvimento estão marcadas por diferentes capacidades de poder e interesses que são articulados por meio de processos históricos de estruturação de redes. "Desenvolvimento" abarca diferentes visões e posições políticas, variando do interesse em acumulação de poder econômico e político a uma ênfase em redistribuição e igualdade. Em conseqüência, lutas de poder são comuns entre atores, internamente às instituições e entre elas. Nós de poder diferenciado operam dentro de uma rede de relações e se expressam concretamente em disparidades existentes entre, digamos, as capacidades e ações do Banco Mundial e aquelas de uma pequena ONG na Índia. Barros ${ }^{8}$, no seu estudo de movimentos e políticas ambientais globais, cunhou a noção de "agentes nucleares", aqueles com mais poder para influenciar a configuração e tendências de um campo (no seu caso, as Nações Unidas, o Banco Mundial e as ONGs mais influentes). Os atores e as instituições mais poderosos do campo de desenvolvimento são designados, às vezes pejorativamente, pelo rótulo "indústria do desenvolvimento". Eles se empenham na reprodução do campo como um todo, já que seus próprios interesses são intimamente conectados à existência do campo. Os atores e instituições menos poderosos são grupos locais vulnerabilizados por iniciativas de desenvolvimento que destroem as relações entre povos indígenas, seus territórios e culturas - como os reassentamentos forçados para a construção de represas - e provêem o cenário mais óbvio da vulnerabilidade de populações locais vis-à-vis ao "desenvolvimento". A natureza da distribuição de poder dentro do campo do desenvolvimento dependerá dos processos por meio dos quais as redes são formadas e das características das intervenções institucionais decorrentes do drama do desenvolvimento.

\section{CRIANDO REDES E CONSÓRCIOS: A CONSTRUÇÃO DE INSTITUIÇ̃̃ES}

Redes relacionadas à expansão e ao crescimento econômicos não são novas. Desde a Revolução Industrial, por exemplo, elas têm operado na construção de projetos de infra-estrutura de grande escala (PGEs), como canais, ferrovias, represas e outras grandes obras que formam a quintessência dos chamados "projetos de desenvolvimento"9. Os PGEs têm características estruturais quelhes permitem ser tratados como "expressões extremas" do campo do desenvolvimento: o tamanho do capital, territórios e quantidade de pessoas que eles controlam; seu grande poder político; a magnitude de seus impactos ambientais e sociais; as inovações tecnológicas que freqüentemente criam; e a complexidade das redes que eles engendram ${ }^{10}$. Eles juntam quantidades impressionantes de capital financeiro e industrial, assim como de elites e técnicos estatais e trabalhadores, fundindo níveis de integração locais, 
regionais, nacionais, internacionais e transnacionais ${ }^{11}$. Como uma forma de produçãoligada à expansão de sistemas econômicos, os PGEs conectam áreas relativamente isoladas a sistemas mais amplos de mercados integrados. Fluxos não-lineares de trabalho, capital e informação entre tais projetos têm acontecido em escala global ${ }^{12}$. Os projetos de grande-escala têm se apoiado em instituições poderosas - tais como organizações governamentais e multilaterais, escolas de engenharia, bancos e corporações industriais -, que têm desempenhado papéis importantes na economia política dos últimos dois séculos. Muitas dessas instituições se tornaram centros de difusão de idéias sobre novos e até maiores projetos; sobre inovações tecnológicas; e sobre categorias, modelos e ideologias de progresso e expansão industrial.

Por que deveríamos nos importar com essas conexões históricas? Precisamente porque o campo do desenvolvimento herda muitas das crenças e práticas geradas e transmitidas internamente ao campo dos projetos de grande escala. Não é uma casualidade o fato que nos bancos multilaterais, por exemplo, antes do impacto reformista do movimento ambientalista, projetos de infra-estrutura de grande escala tenham sido, por muitos anos, alguns dos principais itens de suas carteiras. Os circuitos que vinculam projetos nas escalas nacionais aos globais têm construído uma rede multilocalizada por meio da qual informação e pessoas circulam. Soluções técnicas e administrativas são intercambiadas e algumas vezes melhoradas em projetos apresentados como vitrines para a implementação de novos métodos e tecnologias. Por causa de seus enormes impactos ambientais e sociais, os PGEs mostram claramente o desequilíbrio das relações de poder entre populações locais e outsiders desenvolvimentistas. Por outro lado, esses projetos têm também causado um aumento na capacidade de reação de atores locais na forma de movimentos sociais e ONGs. As pessoas passaram a entender as desigualdades inerentes a esse tipo de expansão econômica. O capital estrangeiro, vários tipos de profissionais e técnicos expatriados comumente ficam com a maior parte das riquezas produzidas em tais empreendimentos.

As conexões entre diferentes PGEs, assim como a continuidade intergeracional que existe em muitas das profissões neles envolvidas, tornam mais evidente a necessidade de traçar conexões e continuidades similares em outras áreas centrais do campo do desenvolvimento. O Banco Mundial, o "Vaticano do desenvolvimento internacional" exemplifica bem essa questão. Nos seus primeiros anos, foi o herdeiro não só de muitos discursos coloniais sobre o que viria a ser conhecido como "países do Terceiro Mundo", mas também de funcionários das antigas administrações coloniais que estavam desaparecendo ${ }^{14}$. O conhecimento sobre PGEs também permite entender o desenvolvimento como uma força expansiva historicamente intrínseca à globali-
[11] Inspirado em Julian H. Steward (Theory of culture change: The methodology of multilinear evolution. Urbana e Chicago: University of Illinois Press, 1972), interpreto os níveis de integração como um espectro formado por níveis locais, regionais, nacionais, internacionais e transnacionais, com poderes diferentes de estruturação. Para fins de simplicidade e clareza, faço a seguinte equação: o nível local corresponde à localização de nossas experiências fenomenológicas imediatas diárias, isto é, à série de lugares onde uma pessoa ou um grupo executam atividades diárias regulares, interagindo com ou sendo expostos a diferentes redes e instituições sociais. O nível regional corresponde à definição político-cultural de uma região dentro de um nação, como o Sul dos Estados Unidos, ou a Galícia, na Espanha. Os níveis nacionais, internacionais e transnacionais se referem à existência do Estado-nação $\mathrm{e}$ às diferentes relações dentro, fora $\mathrm{e}$ através dele.

[12] Ribeiro, G. L.Transnational capitalism and hydropolitics in Argentina. Gainesville: University of Florida Press, 1994; e idem. "Ethnic segmentation of the labor market and the 'Work Site Animal': fragmentation and reconstruction of identities within the world system". In: Schneider, Jane e Rapp, Rayna (orgs.). Uncovering hidden histories. Berkeley: University of California Press, 1995, pp. 336-350.

[13] Rich, Bruce. Mortgaging the earth: The World Bank, environmental impoverishment, and the crisis of development. Boston: Beacon Press, 1994, p. 195 .

[14] Kraske,Jochen eoutros.Bankers with a mission: The presidents of the World Bank, 1946-91. Oxford: Oxford University Press, 1996, p. 136. 
zação, e revela tal expansão como intervenções planejadas que dependem do estabelecimento de redes de engenheiros, técnicos, políticos, lobistas, servidores públicos, e capitalistas financeiros e industriais. Os relacionamentos pessoais são de extrema importância para navegar através das complexas redes de interesses que existem dentro e ao redor dos projetos; os relacionamentos também são as fundações sobre as quais muitas redes, intra e intercategorias profissionais, se constroem e propiciam diversos tipos de intermediações. Essas redes freqüentemente se articulam a interesses locais, regionais, nacionais, internacionais e transnacionais. Elas são perfeitas para revigorar o campo do desenvolvimento mais amplo e complexo porque permitem o estabelecimento de distintas coalizões, que são freqüentemente ad hoc, entre vários atores do campo. Ao mesmo tempo em que essa flexibilidade permite alianças pragmáticas e algumas vezes heterodoxas, que podem provar ser eficazes em muitas circunstâncias, ela também é responsável por uma certa falta de transparência e de responsabilidade nas prestações de contas.

Apesar de seu papel vital em manter a sinergia do campo do desenvolvimento, as redes são fluidas demais para prover a regularidade, estabilidade, planejamento racional e capacidade de previsão necessários às intervenções desenvolvimentistas. A pragmática criação de redes é um instrumento cuja eficiência se reflete na forte habilidade que as redes têm em mover-se de cenários locais a nacionais, internacionais e transnacionais. As redes também levam a uma perda relativa de homogeneidade entre os sujeitos coletivos resultantes. Estes, em geral, existem como coalizões orientadas a uma tarefa que, uma vez completada, redunda no desmantelamento do grupamento ad hoc. Esse o motivo pelo qual as redes podem ser caracterizadas como atores pragmáticos, fragmentados, disseminados, circunstanciais e até voláteis. Sua força vem dessas características e de uma heterogeneidade que as capacita a estar à altura de um campo político e econômico variante, com mais eficácia do que atores tradicionais que, em geral, estão limitados pela necessidade de coerência e coesão internas em termos ideológicos, organizacionais e políticos (com os conseqüentes pesos institucionais e grandes investimentos de energia). A unidade aparente desses atores tradicionais serve como uma identidade externa que os qualifica como representantes de um segmento, uma corporação ou de interesses precisamente delimitados. Mas a debilidade das redes advém igualmente do seu pragmatismo: ele as impede de se tornarem atores que poderiam ter uma presença mais duradoura e forte, se consolidadas em um sujeito mais homogêneo e coerente com um objetivo programático compartilhado. Em conseqüência, às redes se juntam outras entidades dentro do campo do desenvolvimento, as instituições. 
Quando redes chegam ao ponto de ter interesses e objetivos bem definidos e duradouros, elas tendem a se tornar instituições baseadas não somente em relacionamentos pessoais, mas também em racionalidade burocrática. Instituições são as cristalizações de redes que têm projetos claros em vista e que podem ser realizados dentro de um futuro previsível. A construção de instituições envolve uma grande quantidade de cooperação técnica e monitoramento, e é, também, uma forma de domesticar o ambiente imprevisível onde ocorre o "desenvolvimento".

As instituições de desenvolvimento são burocracias de tamanhos e complexidades diferentes. Como Max Weber ${ }^{15}$ apontou, burocracias são uma forma de dominação, de exercer poder. Quanto maiores as iniciativas de desenvolvimento, maior a burocracia relacionada a elas e mais forte sua capacidade de exercer poder, principalmente sobre instituições e atores que operam em níveis mais baixos de integração. Com suas hierarquias, regras e necessidades reprodutivas, burocracias são máquinas de indiferença:

Prestação de contas, Webernos diz, é do que se trata a burocracia, e prestar contas é aquilo em que muitos burocratas investem muita energia para abortarouevitar.Um cínico poderia definirpodercomo o direito de não prestarcontas ${ }^{16}$.

Esse "direito a não prestar contas" tem motivado muitas reações e muita oposição a burocracias de desenvolvimento em escala mundial. Redes contra-hegemônicas ou regulatórias, compostas por ONGs, movimentos sociais, sindicatos, igrejas etc., têm tido papéis fundamentais na proteção dos interesses de populações locais contra a grande quantidade de poder acumulado por instituições de desenvolvimento. Muitas das agora freqüentes críticas expressadas pelas próprias instituições de desenvolvimento sobre a natureza de suas operações devem ser entendidas à luz das pressões e lutas dessas redes contra-hegemônicas ou regulatórias. O fato de burocratas ou tecnocratas de agências de desenvolvimento criticarem seus próprios modos de operação não é necessariamente uma contradição, como pode parecer à primeira vista. É inerente à racionalidade das burocracias produzir sua própria crítica, como uma forma de disseminar e naturalizar a própria estrutura burocrática que elas parecem criticar e à qual, algumas vezes, parecem se opor ${ }^{17}$. De fato, e isso é especialmente verdadeiro na história do desenvolvimento, a capacidade de produzir desculpas por erros cometidos, de reciclar formulações e de criar novas panacéias faz parte dos "idiomas de auto-exoneração"18 em muitas instituições ${ }^{19}$.

As burocracias também são campos de poder. Crítica e oposição às políticas mais fortes institucionalmente relacionam-se a lutas de
[15] Weber, Max. "Sociología de la dominación". In: Economía y Sociedad. México: Fondo de Cultura Económica, 1977, pp. 695-1117.

[16] Herzfeld, Michael. The social production of indifference: exploring the symbolic roots of western bureaucracy. Chicago: The University of Chicago Press, 1992, p. 122.

[17] Ibidem.

[18] Ibidem, p.46.

[19] Inspirado no conceito de teodicéia de Weber, um conceito relacionado às várias formas pelas quais sistemas religiosos procuram interpretar a aparente contradição de persistência maléfica em um mundo divinamente ordenado, Herzfeld diz que a "teodicéia secular [...] provê meios sociais para as pessoas lidarem com a decepção. O fato de que os outros nem sempre contestam até mesmo as mais absurdas tentativas de explicar o fracasso [pode ser] a evidência de uma orientação muito prática que se recusa a minar as convenções de auto-justificação porque virtualmente todos $[. .$.$] podem preci-$ sar utilizá-las no curso da vida" (ibidem,p. 7). 
[20] Rich,op.cit.

[21] Weber, op.cit.,p. 708 .

[22] Wolf, Eric. "Kinship, friendship, and patron-client relations in complex societies." In: Pathways of power: building an anthropology of the modern world. Berkeley: University of California Press, 2001 [1966], pp. 166-183, p. 174.

[23] Ibidem, p.179.

[24] Ibidem.

[25] Ribeiro, Transnational Capitalism and hydropolitical in Argentina, op.cit.

[26] Os argumentos seguintes estão baseados no meu estudo sobre a construção da represa de Yacyretá(ibidem). Mantendo as diferenças em mente, consorciação também acontece em projetos menores e naqueles que são implementados em nome do "desenvolvimento sustentável" (Pareschi, Carolina C.PD/A e PP-G7: construindo modelos de ação e interação do desenvolvimento sustentável. 2001 (mimeo). poderque se desenvolvem dentro e fora das instituições em certas conjunturas. A disputa dentro do Banco Mundial sobre o projeto de desenvolvimento da bacia do rio Narmada, na Índia,é um exemplo de quão intricadas são tais lutas políticas ${ }^{20}$. A crítica, entretanto, tem limites. Apesar dos esforços que as instituições fazem para censurar seus funcionários, às vezes eles fazem alianças com redes contra-hegemônicas ou regulatórias por sua própria conta e risco.A punição de tal heresia é freqüentemente a demissão pura e simples; a ortodoxia e a teodicéia burocráticas precisam parecer imaculadas.

Max Weber ${ }^{21}$ já tinha percebido a impossibilidade de uma forma pura de dominação burocrática. Dentro do campo do desenvolvimento, relações pessoais são críticas em momentos relevantes tais como o recrutamento de novos funcionários e a promoção de aliados políticos. Na verdade, a proeminência de "amizades instrumentais", um grande motor na criação de redes, é tão forte em grandes organizações burocráticas que as redes normalmente se cristalizam em panelinhas internamente a esses cenários ${ }^{22}$. Especialmente em situações de desequilíbrio de poder, as panelinhas têm "funções instrumentais importantes ao tornarem uma situação imprevisível em algo mais previsível e ao fornecerem apoio mútuo contra surpresas perturbadoras, internas ou externas" 23 . Wolf conclui que "uma perspectiva interessante" sobre grandes organizações "pode ser obtida olhando-as enquanto organizações de aprovisionamento de panelinhas, ao invés do contrário" 24 .

As instituições também se tornam parte de várias redes dentro do campo do desenvolvimento. Elas criam redes por meio de complexos processos históricos e políticos. Denominei esses processos de "consorciação", para chamar a atenção para sua entidade resultante: o consórcio ${ }^{25}$. As instituições são os blocos de construção dos consórcios que, por sua vez, transformam-se em novas instituições, as quais podem virar as unidades de novos e mais complexos consórcios. A consorciação é fundamental para entender o campo do desenvolvimento, já queé o processo galvanizante que transforma redes de instituições em consórcios destinados a cumprir papéis delimitados conforme definido por um dado "projeto" ${ }^{26}$. A consorciação é um processo político comandado por grupos de poder que operam em níveis mais elevados de integração. É um encadeamento que mediante a organização de novas entidades orientadas a tarefas econômicas e administrativas - une, de fato, dentro de um projeto, instituições e capitais internacionais, nacionais e regionais. É uma forma de reforçar relacionamentos capitalistas de modo piramidal, em que níveis mais elevados hegemonizam níveis mais baixos. O consórcio é a entidade social, econômica, e política concreta que articula diferentes grupos de poder. O processo político-econômico de criação de 
consórcios afeta diretamente o potencial dos projetos de desenvolvimento. A consorciação significa que os projetos reforçam a competição e a concentração de capital e poder entre firmas capitalistas; ela facilita o processo de concentração de capital e poder eliminando competidores mais fracos e cooptando alguns poucos selecionados.

A consorciação envolve um processo de mão dupla. Por um lado, permite a pequenas unidades selecionadas participarem como parceiros juniores em tarefas maiores do que sua capacidade financeira, tecnológica e administrativa permitiria. Por outro lado, é uma forma de facilitar o acesso de corporações maiores a novos mercados, que são freqüentemente protegidos ou altamente disputados. Por meio de diferentes discursos sobre o potencial de um projeto para o desenvolvimento local, regional enacional, os parceiros mais fracos na corrente associativa legitimam suas reivindicações de maior participação. O desenvolvimento local ou regional é, assim, um argumento comum entre companhias que operam em nível local ou regional, competindo com corporações nacionais ou internacionais. Da mesma forma, o desenvolvimento nacional é o argumento usado por corporações nacionais para defender seus interesses perante o capital internacional e transnacional. Dada a característica de mão dupla da consorciação, os discursos sobre desenvolvimento local, regional ou nacional podem ser um argumento que os parceiros mais fortes, isto é, os representantes das concentrações maiores de capital ou poder, usem para legitimar a necessidade do projeto. A eloqüência do argumento desenvolvimentista é evidente quando a cooptação de unidades menores é necessária.

Consórcios são um meio que as corporações têm para otimizar o uso de diferentes redes que precisam ser ativadas para realizar diferentes objetivos econômicos e políticos. Por exemplo, um consórcio operando na junção dos sistemas internacionais e nacionais, e formado por grupos de poder nacionais e transnacionais, pode fazer lobby tanto junto a instituições nacionais quanto a internacionais e multilaterais. Formar um consórcio sempre implica uma negociação, um processo baseado não só em critérios econômicos e administrativos. A intervenção de poderosos atores - os controladores ou donos de capitais estatais, nacionais e transnacionais - gera um campo de negociações de poder que é politicamente estruturado. Escolher parceiros nacionais, por exemplo,é uma decisão estratégica que leva em consideração que forte apoio político dentro do Estado nacional pode ter mais valor que apoio financeiro ou técnico. Na verdade, a definição da participação de cada parceiro em um contrato é devida tanto a articulações políticas, à criação de redes e lobby, quanto a avaliações técnicas da capacidade produtiva, financeira e técnica de um determinado parceiro. A consorciação é, assim, ao mesmo tempo, um instrumento de expansão 
[27] Manheim, Karl. Ideology and utopia. New York: Harvest Books, s/d.; Ricoeur, P. Lectures on ideology and utopia. New York: Columbia University Press, 1986.

[28] Ribeiro, G. “Environmentalism and sustainable development: ideology and utopia in the Late Twentieth Century". Environment, Development and Reproduction. Research Texts 2. Rio de Janeiro: Instituto de Estudos da Religião, 1992.

[29] Escobar, Arturo. Encountering development: the making and unmaking of the Third World. Princeton: Princeton University Press, 1995.

[30] Rist, op.cit., p. 218.
[31] Dahl, Gudrun e Hjort, Anders. "Development as message and meaning". Ethnos, n² 49, 1984, pp. 165 85, p. 166.

[32] Maybury-Lewis, David. Development and human rights: the responsibility of the anthropologist. Trabalho apresentado no Seminário Internacional sobre Desenvolvimento e Direitos Humanos, ABA (Associação Brasileira de Antropologia) Unicamp, Campinas, 1990, p. 1 . econômica e um meio de estabelecer um campo político no qual intermediários de diferentes redes estabelecem as condições para participar em um projeto concreto. Desde os pontos mais baixos até os mais altos, desenvolvimento é a ideologia/utopia que cimenta os diversos interessados, redes e instituições.

\section{DESENVOLVIMENTO: UMA IDEOLOGIA E UTOPIA DE EXPANSÃO}

Ideologias e utopias são essencialmente relacionadas a poder. Elas expressam disputas sobre interpretações do passado (ideologia) ou do futuro (utopia), e lutam para instituir hegemonia estabelecendo certas visões retrospectivas ou prospectivas como a verdade, como a ordem natural do mundo ${ }^{27}$. Desde a Segunda Guerra Mundial, o desenvolvimento como um sistema de crenças tem sempre sido marcado por leituras particulares do passado e por formulações sobre o futuro em escala global ${ }^{28}$. Na sua análise sobre desenvolvimento, Escobar ${ }^{29}$ o considera equivalente ao discurso colonial. De um ângulo diferente, Gilbert Rist ${ }^{30}$ trata desenvolvimento como um sistema de crenças organicamente relacionado à expansão mundial de sistemas de mercados integrados e como o "slogan mobilizador de um movimento social que criou organizações e práticas messiânicas".

O fim da União Soviética (1989-1991) provocou fortes rearranjos do sistema mundial e abriu o caminho para a consolidação de diferentes ideologias e utopias de alcance global. Na década de 1990, dois discursos relacionados tornaram-se hegemônicos: desenvolvimento sustentável e globalização. Ambos parecem estar alcançando seus limites como slogans para o século XXI, abrindo uma nova rodada de lutas ideológicas e utópicas, assim como novas oportunidades de mudança. Para reformas radicais ou menores do desenvolvimento e da cooperação, um conhecimento crítico dos sistemas de valor e da gramática do desenvolvimento é tão crucial quanto expor sua estruturação como um campo de poder. A exposição da obsolescência dos discursos hegemônicos é sempre necessária a fim de ir além deles. $\mathrm{O}$ que está em jogo é a aceitação pelos atores sociais de novos discursos sobre seus destinos.

Desenvolvimento é um dos discursos mais inclusivos no senso comum ena literatura especializada. Sua importância para a organização de relações sociais, políticas e econômicas fez com que antropólogos o considerassem como "uma das idéias básicas da cultura européia ocidental moderna" ${ }^{11}$, "algo como uma religião secular", inquestionada, já que "se opor a ela é uma heresia quase sempre severamente punida"32.A amplitude e as múltiplas facetas do desenvolvimento são o que permite suas muitas apropriações e leituras freqüentemente divergentes. A plasticidade do discurso sobre desenvolvimento écentral para assegurar sua 
viabilidade continuada; ele está "sempre em processo de transformação, de cumprir promessas" 33 . A variação das apropriações da idéia de desenvolvimento, assim como as tentativas de reformá-la expressamse nos numerosos adjetivos que formam parte da sua história: industrial, capitalista, para dentro, para fora, comunitário, desigual, dependente, sustentável, humano. Essas variações e tensões refletem não apenas as experiências históricas acumuladas por diferentes grupos de poder em suas lutas por hegemonia internamente ao campo do desenvolvimento, mas também diferentes momentos de integração do sistema capitalista mundial.

Desde o século XIX, e de maneira mais intensa após a Segunda Guerra Mundial, o passo acelerado da integração do sistema mundial demandou ideologias e utopias que pudessem dar sentido às posições desiguais dentro do sistema, que pudessem prover explicações por meio das quais povos colocados em níveis mais baixos pudessem acreditar que haveria uma solução para sua situação "atrasada". Não é por acidente que a terminologia do desenvolvimento tenha envolvido normalmente o uso de metáforas que se referem a espaço ou a ordem de forma hierarquizada: desenvolvido/subdesenvolvido, adiantado/atrasado, Primeiro Mundo/Terceiro Mundo etc. Essa hierarquia é instrumental, serve para fazer crer na existência de um ponto que pode ser atingido caso siga-se um tipo de receita mantida por aqueles Estadosnação que lideram a "corrida" para um futuro melhor. Ao usar o termo "desenvolvimento", em vez de acumulação ou expansão, conotações indesejadas são evitadas, como a diferença de poder entre as unidades do sistema (internamente ou entre Estados-nação) em termos econômicos, políticos e militares; evita-se também a percepção de que desenvolvimento é "uma expressão simples de um pacto entre grupos internos e externos interessados em acelerar a acumulação" 34 .

"Desenvolvimento" opera como um sistema de classificação, estabelecendo taxonomias de povos, sociedades e regiões. Edward Said e Arturo Escobar mostraram a relação entre a criação de geografias e a ordem e poder mundiais 35 . Pode ser dito com Herzfeld que "a criação e manutenção de um sistema de classificação tem sempre [...] caracterizado o exercício de poder em sociedades humanas" ${ }^{36}$. As classificações freqüentemente produzem estereótipos úteis para sujeitar pessoas por meio de simplificações que justificam a indiferença à heterogeneidade. Os estereótipos quase não conseguem esconder suas funções de poder sob a superfície do idioma do desenvolvimento e da cooperação cujo léxico é cheio de dualismos que se referem, de forma estática ou dinâmica, a estados transientes ou a relacionamentos de subordinação (desenvolvido/subdesenvolvido, países em desenvolvimento, mercados emergentes ${ }^{37}$ etc.). Estereótipos podem também se tornar palavras-chave — tais como assistên-
[33] DSA (Department of Social Anthropology). Development as ideology and folk model. A research programme of the Department of Social Anthropology at the University of Stockholm, s.d.,pp. 4-5.

[34] Furtado,Celso.Criatividade edependência na civilização industrial. Rio de Janeiro: Paz e Terra, 1978, p. 77.

[35] Said, Edward. Culture and imperialism. New York: Alfred A. Knopf, 1994; e Escobar, op. cit.

[36] Herzfeld, op.cit., p. 110.

[37] VerPerrote outros,op.cit.,p.189. 
[38] Rist, op.cit., p. 241.

[39] Ver Delvaille, Jules. Essai sur l'histoire de l'idée de progrès jusqu'à la fin $d u$ XVIII siècle. Genève: Slatkine Reprints, 1969; e Dodds, E. R. The ancient concept of progress, and other essays on Greek literature and belief. Oxford:Oxford University Press, 1973.

[40] Binder, Leonard. "The natural history of development theory". Comparative Studies in Society and History, $\mathrm{n}^{\mathrm{2}} 28,1986$, pp.10-12.

[41] Ribeiro, "Environmentalism and sustainable development”, op.cit.

[42] Appadurai, Arjun. "Disjuncture and difference in the global cultural economy". In: Featherstone, Mike (org.). Global culture. Londres: Sage Publications, 1990, pp.9-10.

[43] Sobre etnodesenvolvimento, ver os textos de Stavenhagen, Rodolfo. "Etnodesenvolvimento: uma dimensão ignorada no pensamento desenvolvimentista". Anuário Antropológico, vol. 84, 1985, pp. 11-44; e Davis, Shelton H. "Indigenous peoples, environmental protection and sustainable development (a sustainable development occasional paper)". International Union for Conservation of Nature and Natural Resources,1988, por exemplo. No livro Autodesarrollo indigena en las Américas (IWGIA, Copenhagen, 1989), a expressão etnodesenvolvimento foi substituída por "auto-desenvolvimento indígena", aparentemente porque os participantes indígenas do simpósio organizado pelo Grupo de Trabalho Internacional para Assuntos Indígenas "não gostaram do conceito de 'etnodesenvolvimento' e preferiram conceber desenvolvimento como um tipo de auto-determinação" (ibidem, p. 10). Leituras antropológicas críticas de ideologias/utopias ocidentais colocam dilemas que podem atingir nossas próprias predileções políticas. Responsabilidade social, transparência e prestação de contas, por exemplo, claramente não são categorias universais. No seu estudo comparativo de burocracias, Herzfeld concluiu que essas categorias formam "uma amálgama socialmente produzida, culturalmente saturada de idéias sobre pessoa, presença e política. [Seus] significados são culturalmente específicos e sua operação é restringida pelas formas mediante as cia, ajuda, doadores/recipientes, doadores/beneficiários - que claramente indicam, de forma pouco sutil, o desequilíbrio de poder entre duas séries de atores e legitimam a transformação de uma série deles em objetos de iniciativas de desenvolvimento.

A alegação do desenvolvimento acerca de sua própria inevitabilidadeé mais outra faceta de suas pretensões universalistas. O fato de "desenvolvimento" ser parte de um amplo sistema de crenças marcado por matrizes culturais do Ocidente coloca grandes limitações a tais pretensões universalistas. É também mais uma razão que explica por que, em muitos contextos não-ocidentais, vários povos e agentes locais relutam em se tornar sujeitos do desenvolvimento. É difícil discordar da afirmação de que não há método universal para alcançar uma "boa vida" ${ }^{8}$. A pré-história do desenvolvimento reflete matrizes discursivas ocidentais como a crença no progresso (que pode ser traçada até a Grécia antiga39) e outras relacionadas a momentos tão decisivos quanto o Iluminismo - crucial para o desenrolar dos pactos econômicos, políticos e sociais da modernidade ocidental e suas ideologias e utopias associadas (industrialismo, secularismo, racionalização e individualismo, por exemplo). Leonard Binder reconhece, em certas teorias de desenvolvimento, uma matriz ainda mais estreita: a imagem dos Estados Unidos "como alguns liberais gostariam que nós fossemos"40. Mais recentemente, no final dos anos 1980 e no começo dos anos 1990, a idéia de desenvolvimento sustentável reverberava com noções de relacionamentos apropriados entre a humanidade e a natureza, típicas das classes médias urbanas, protestantes, em países como Alemanha, Inglaterra e Estados Unidos41.

Na realidade, desenvolvimento é mais um exemplo de um discurso globalizante, similar ao que Appadurai chama de ideopanoramas "elementos da visão de mundo Iluminista, que consiste em uma concatenação de idéias, termos e imagens, incluindo 'liberdade', 'bemestar', 'direitos', 'soberania', 'representação' e o termo chave 'democracia" "42. Nesse sentido, termos como "etnodesenvolvimento", inventados para se referirem a modelos indígenas de desenvolvimento ou a modelos alternativos que poderiam respeitar valores e culturas locais, são oxímoros. Eles indubitavelmente refletem aspirações legítimas, mas se localizam na linha fina e paradoxal da aceitação do desenvolvimento como uma categoria universal43.

Mencionarei brevemente outras questões antropológicas que tornam problemática a pretensão do desenvolvimento, como ideologia e utopia, ao universalismo. A primeira é a existência de noções de tempo que são radicalmente diferentes ${ }^{44}$. Desenvolvimento depende de uma concepção que compreende o tempo como uma seqüência linear de estágios avançando interminavelmente para momentos melhores. 
Uma implicação desse construto ocidental é que crescimento, transformação e acumulação se tornam princípios-guia de políticas. Mas em muitas sociedades não-ocidentais o tempo é entendido como ciclos de eternos recomeços, o que favorece o florescimento e a consolidação da contemplação, adaptação e da homeostase como pilares de suas cosmologias. Nesta mesma linha, não se pode subestimaro papel do controle do tempo - particularmente do relógio, a mãe da complexidade mecânica - no desenvolvimento econômico nos últimos séculos 45 . Sincronia e capacidade de previsão são a base das relações de trabalho capitalistas e industriais. Outro grande divisor de águas é a transformação da natureza em mercadoria, um processo histórico relacionado ao desenrolar do capitalismo e da modernidade ${ }^{46}$ e que parece estar chegando a seu clímax com a exploração, pelo capital, do código da vida (biotecnologia) e da virtualidade (o ciberespaço e outras formas tecnológicas de virtualidade são cada vez mais cruciais para as atividades econômicas). Muitos dos impasses entre atores desenvolvimentistas e povos indígenas são baseados nessa diferença cosmológica. O que para alguns são meros recursos, para outros podem ser lugares e elementos sagrados.

Choques culturais formam o cenário mais amplo onde se localizam as questões de línguas e racionalidade. A língua em geral e a língua escrita em particular são grandes barreiras para a comunicação dentro do campo do desenvolvimento. Para cooperarem, as pessoas precisam entender, e competência comunicativa não é um recurso igualmente distribuído dentro das redes de desenvolvimento. Além disso, a competência lingüística, como percebeu Bourdieu47, não pode ser separada da análise de poder. Quem fala, para quem, através de que mídia e em quais circunstâncias construídas, são elementos vitais de qualquer processo de comunicação. A relação entre língua escrita e poder é ainda mais evidente, sendo a escrita central para o desenvolvimento de Estados e burocracias, tornando possível, entre outras coisas, apresentar regras como artefatos impessoais ${ }^{4}{ }^{8}$. Herzfeld vincula a idéia de uma língua abstrata perfeitamente independente de seu contexto e o modelo ocidental de racionalidade a um desejo de transcendência típico das "concepções judaico-cristãs e indo-européias sobre a superioridade da mente sobre a matéria" 49 . Para ele, a "habilidade de representar algumas formas de língua" como independentes de seus contextos é onde "o exercício de poder reside" 50 .

O analfabetismo é uma grande barreira dentro do campo do desenvolvimento, principalmente para aqueles projetos que defendem participação local.O planejamento é o coração da iniciativa racional de desenvolvimento. Ele depende do estabelecimento de regras e instruções escritas que precisam ser seguidas - seé que eficiência, objetivos burocráticos e prestação de contas devem ser atingidos. Os projetos são os quais seus operadores e clientes interpretam suas ações. Sua administração de identidade pessoal ou coletiva não pode se tornar independente da experiência social" (op.cit., p. 47).

[44] Lévi-Strauss, Claude. Raça e história. Lisboa: Presença, 1980.

[45] Landes, David S. Revolution in time: clocks and the making of the modern world. Cambridge: Harvard University Press, 1983.

[46] Jameson, Frederic. "Postmodernism, or the cultural logic of late capitalism". New Left Review, n ${ }^{\mathrm{Q}} 146,1984$, pp. 53-92.

[47] Bourdieu, P. “A economia das trocas lingǘsticas". In: Ortiz, Renato (org.). Pierre Bourdieu. São Paulo: Ática, 1983 [1977], pp. 161 ess.

[48] Goody, Jack. The logic of writing and the organization of society. Cambridge: Cambridge University Press 1986.

[49] Herzfeld, op.cit., pp.19-20.

[50] Ibidem, p.119. 
artefatos que sumarizam a necessidade de controle sobre tempo, pessoas e recursos. Práticas contábeis, definições legais, planos, objetivos racionais e o uso de tecnologias são altamente dependentes do compartilhamento do mesmo horizonte cultural e de certos níveis de educação formal. O fracasso de um projeto é quase certo se os atores desenvolvimentistas forem incapazes de fazer com que as pessoas na base entendam o que o projeto é, como deve ser implementado ou usado. Essa charada histórica e sociológica é a raison d'être da cooperação técnica e da capacitação para o desenvolvimento.É também a causa principal de processos como a exportação da inteligência e capacidade de planejamento dos projetos para centros estrangeiros e da fuga de cérebros - dois efeitos perversos que reforçam desigualdades estruturais entre os Estadosnação. Como cultura e educação são determinantes estruturais dos modos de vida das sociedades, e não mudam no ritmo que os projetos de desenvolvimento requerem, expatriados ou outsiders de outras regiões de um mesmo país são freqüentemente enviados para compensar deficiências locais. Seu compromisso com a vida local é temporário. Eles são usualmente membros de redes que se reproduzem em níveis de integração nacionais, internacionais e transnacionais.

É certo que "transformação" é o núcleo duro do desenvolvimento como ideologia e utopia e que, muitas vezes, a transformação é almejada por povos locais de diferentes origens culturais. Sem dúvida, é da natureza de algumas inovações cativar as pessoas, já que a mudanças que trazem tornam suas vidas mais confortáveis, mais seguras e mais saudáveis. São complexas as razões pelas quais algumas pessoas aceitam mudanças e outras não. Mas pelo menos três pontos precisam ser explicitados sobre transformações, mudanças e inovações tecnológicas: (a) a natureza da transformação e do contexto em que a mudança vai ser introduzida define se vai ser bem-vinda ou não; (b) transformações, mudanças e inovações tecnológicas são artefatos culturais que sempre envolvem e afetam sistemas de poder; e (c) elas impactam sistemas sociais, culturais e ambientais em graus variáveis (desde desastres totais a mudanças palatáveis menores). Não há dúvida de que alguns projetos podem aumentar o acesso de uma comunidade à modernidade. Mas é também verdade que "desenvolvimento" não significa mudanças estruturais em distribuição de poder e esta é uma razão de fortes críticas contra ele. Rist coloca essa questão de forma direta: "aqueles com poder não têm interesse em mudanças, não importa que digam o contrário, e aqueles que querem mudanças não têm os meios para impô-las" 51 .

\section{O DESEQUILÍBRIO DE PODER: QUEM É SUJEITO DO DESENVOLVIMENTO?}

"Dramas desenvolvimentistas" são tipos complexos de encontros que juntam atores e instituições locais a outsiders. O fato de outsiders 
pretenderem planejar o futuro de uma comunidadeé indicativo do seu poder diferencial no encontro. Em tais circunstâncias, instala-se uma dicotomia. Por um lado, há os objetivos e racionalidades dos planejadores; por outro lado, o destino e a cultura das comunidades. Antes da existência de um projeto de desenvolvimento, populações locais dificilmente poderiam conceber que seu destino era suscetível de ser seqüestrado por um grupo organizado de pessoas. Na realidade, planejamento - isto é, a determinação antecipada de como uma certa realidade será - implica a apropriação, por parte de outsiders, do poder das populações locais de serem sujeito dos seus próprios destinos. De sujeito de suas próprias vidas, essas populações se tornam sujeitas a elites técnicas prescientes.

Desenvolvimento cria dois tipos de sujeitos, um ativo e outro passivo. "Sujeitos-passivos" são pessoas transformadas em objetos de imperativos desenvolvimentistas. Os reassentamentos forçados representam os casos extremos dessa categoria.A apropriação do projeto por parte da população local é al tamente improvável. Nessa situação, os atores locais em geral se defrontam com opções estranhas, como estabelecer relacionamentos do tipo patrão-cliente com outsiders desenvolvimentistas ou lutar para recuperar o controle sobre suas vidas e ambientes. Na realidade, esses "sujeitos-passivos" inclinam-se a resistir ao desenvolvimento, já que se relacionam com sua faceta mais autoritária. Mas desenvolvimento também cria "sujeitos-ativos". Os agentes do desenvolvimento são pessoas locais propensas a se tornar aliadas de iniciativas de desenvolvimento porque podem identificar benefícios e interesses em comum com os outsiders. A existência desses dois tipos de sujeitos mostra que a apropriação das iniciativas desenvolvimentistas depende altamente de duas variáveis diferentemente distribuídas internamente ao drama desenvolvimentista. Uma é acesso a poder, a ser capaz de controlar seu próprio ambiente e evitar ser o objeto da vontade de outsiders ou dos imperativos de forças estruturais expansionistas e sem rosto. A outra é acesso a conhecimento e informação que capacitem os atores a entender o que está acontecendo e, mais importante ainda, o que vai acontecer com eles. Resistência ou participação são os resultados das formas em que essas variáveis são combinadas. A autoconfiança dos atores locais e a apropriação dos desígnios de um projeto só podem prosperar quando os atores sentem que têm poder sobre seu ambiente.

Há dois modos correntes de gerar sujeitos-ativos/passivos e de lidar com eles.A abordagem "de-cima-para-baixo" tende a criar "sujeitos-passivos". Esse modo autoritário está baseado em redes que cooptam elites locais, não estabelecem políticas compensatórias para aqueles impactados pelos projetos e não têm preocupação com modelos e culturas locais. A abordagem "de-baixo-para-cima" pretende criar 
[52] Sobre isso, ver Marsden, David. "Indigenous management and the management of indigenous knowledge". In: Wright, Susan (org.). Anthropology of organizations. Londres: Routledge, 1994, pp.41-55.

[53] Barbosa, Lívia. Igualdade e meritocracia. a ética do desempenho nas sociedades modernas. Rio de Janeiro: Fundação Getúlio Vargas Editora, 2001, p. 135.

[54] Wolf. E. "Aspects of group relations in a complex society: Mexico". In:Pathways of power: building an anthropology of the modern world. Berkeley: University of California Press, 2001 [1956], pp. 124-138, p. 138 .

[55] Ibidem "sujeitos-ativos" e é mais amigável à apropriação do projeto por parte da população local.Éverdade que esse modo é mais sensível a culturas e modelos locais, incluindo modelos locais de administração ${ }^{52}$. Mas esse modo participativo acaba sendo uma tentativa de compensar a perda estrutural de poder que caracteriza as relações entre populações locais e outsiders quando um projeto é iniciado. Participação e parceria tornam-se jargões da moda que não conseguem mascarar o fato de que todos, no drama desenvolvimentista, sabem onde se localiza o poder máximo nas tomadas de decisões.

Ambas as abordagens geralmente compartilham uma noção instrumental de cultura. Cultura se torna uma "tecnologia gerencial de intervenção na realidade" 53 . Tal definição funcional concebe a cultura como um conjunto de comportamentos e significados inter-relacionados, ajustados e coerentes que podem ser identificados evalorizados em termos de seus impactos positivos ou negativos sobre os objetivos a ser atingidos. Essa noção de cultura cabe bem no campo do desenvolvimento porque se ajusta perfeitamente à terminologia e racionalidade dos planejadores. Mas expressa mal ao menos duas importantes considerações sobre "cultura": (a) contradições e incoerências fazem parte da experiência humana; e (b) cultura está inserida em e atravessada por relações de poder historicamente definidas (desta forma, mudança cultural sempre se relaciona a mudança de poder).

Certamente, qualquer que seja a abordagem, "de-cima-parabaixo" ou "de-baixo-para-cima", poder e sistema político locais sempre serão impactados por intervenções desenvolvimentistas. Dadas as características dos processos de criação de redes e de consorciação típicos do campo do desenvolvimento, os sistemas de poder local passam a ser módulos de circuitos mais amplos de poder comandados por instituições de níveis mais elevados. Como sabemos, instituições e atores transnacionais, internacionais, nacionais e regionais tendem a ter mais poder dentro dos processos de criação de redes e consórcios porque eles já começam com mais recursos. A abordagem autoritária "de-cima-para-baixo" tende a reforçar diferenças previamente existentes em termos de classe, gênero, idade, raça e etnicidade. Em contraste, a abordagem participativa "de-baixo-para-cima" tende a introduzir novas lideranças, assim criando novas tensões dentro dos sistemas de poder e político preexistentes.

Ambas as abordagens produzem "intermediários" 54 que normalmente acumulam uma grande quantidade de poder. Tais intermediários conectam as interseções de diferentes níveis de integração e servem aos interesses dos grupos que intermedeiam. Mas "eles também têm que manter um controle sobre [as] tensões (entre os grupos que servem), senão o conflito torna-se incontrolável e mediadores melhores tomam seus lugares" 55 . Em conseqüência, esse tipo de intermediá- 
rios-controladores prolifera dentro do campo do desenvolvimento e consome muitos dos seus recursos. Eles criam suas próprias redes de poder (compostas por membros de ONGs, consultores, funcionários de agências multilaterais, líderes de sindicatos e movimentos sociais, políticos etc.), nas quais muito da cooperação técnica de fato acontece. Os intermediários são necessários em qualquer campo de desenvolvimento, já que mediações são intrínsecas aos processos de criação de redes e de consorciação. Mas para aumentar a qualidade da cooperação, os intermediários-controladores, isto é, os mediadores especializados em acumular poder pessoal, precisam ter seu poder regulado. Muitos dos resultados dos projetos de desenvolvimento relacionamse à natureza do sistema de intermediação e aos efeitos e distorções de poder que podem gerar.

\section{DESAFIOS PROGRAMÁTICOS}

Neste artigo, apresentei as principais limitações e pressões que afetam a cooperação técnica e o desenvolvimento. Não há soluções fáceis para os conflitos de poder criados pelo campo do desenvolvimento. Somente mudando as características da distribuição de poder dentro desse campo é que a cooperação técnica e o desenvolvimento de fato mudarão. Isso implica que todos os atores e instituições das redes têm de fazer política consciente e constantemente para manter seus interesses vivos. A socialização do conhecimento de riscos e oportunidades envolvendo mudanças trazidas pelo desenvolvimento é importante para melhorar a qualidade da informação que os atores manipulam nessas arenas políticas. Em conseqüência, as redes precisam ser composições democráticas de instituições e atores com a capacidade real de decidir e intervir, principalmente se o resultado desses processos de tomada de decisões não agradar aos interesses mais poderosos envolvidos em um projeto específico. Para alcançar esses objetivos, esferas públicas de discussão e decisão de questão de desenvolvimento precisam ser promovidas, multiplicadas, tornadas mais inclusivas e conseqüentes. A difusão de uma pedagogia democrática deveria atravessar todo o campo do desenvolvimento e suas redes, de administradores e funcionários estatais de alto nível a lideranças de base. O processo associativo típico do campo do desenvolvimento deveria ser aberto aos participantes de forma a igualar o poder de atores operando em todos os níveis de integração. Essas são tarefas importantes para aqueles interessados em transparência, responsabilidade social e fortalecimento da sociedade civil. Eles encontrarão muitas resistências entre poderosos atores interessados no status quo e entre aqueles para os quais a democracia não é um valor. 
[56] Ribeiro, G. "Cybercultural politics: political activism at a distance in a transnational world". In: Alvarez, Sonia, Dagnino, Evelina e Escobar, Arturo (orgs.).Cultures of politics/politics of culture: revisioning latin american social movements. pp.325-352.

Recebido para publicação em 15 de julho de 2007.

\section{NOVOS ESTUDOS}

CEBRAP

80, março 2008

pp. 109-125
Para avançar no mundo globalizado, onde multiculturalismo é cada vez mais um tema político transnacional, devemos admitir que "desenvolvimento" não é exatamente o objeto de desejo de todos. Preferivelmente, perspectivas muito mais abertas devem ser promovidas, visões sensíveis a diferentes contextos culturais e políticos. Concomitantemente à distribuição de poder internamente ao campo do desenvolvimento, diferentes princípios e sensibilidades precisam ser disseminados. Cosmologias e idiomas de desenvolvimento precisam ser radicalmente reformados. "Desenvolvimento" não pode insistir em supor que o Ocidente é universal. "Cooperação técnica" não pode continuar usando uma língua contaminada com metáforas de desigualdade e hierarquia. Se populações e instituições locais não se perceberem como "sujeitos ativos" do desenvolvimento, a apropriação dos projetos por parte das populações locais continuará sendo um problema e a cooperação técnica continuará a reforçar desigualdades estruturais entre Estados-nação.

Os processos de globalização, principalmente aqueles relacionados a novas tecnologias de comunicação, estão promovendo muitas mudanças nos relacionamentos entre cenários locais e globais. Neste quadro, a posição dos sujeitos locais tem evoluído para formas que podem fazer a balança pender para o lado de abordagens mais participativas dentro do campo do desenvolvimento. Apesar de sua distribuição desigual, a internet está aumentando a capacidade de intervenção das ONGs e movimentos sociais. Oespaço público virtualé o ambiente tecno-simbólico da comunidade transnacional imaginada-virtual, além de ser um instrumento útil para reforçarvozes locais e articulações de atores políticos heterogêneos no mundo transnacional56.

Em um planeta mais integrado, novos desafios aparecem e demandam elites políticas e técnicas cosmopolitas inclinadas a aceitar o campo do desenvolvimento global como uma comunidade heteroglóssica, na qual desequilíbrios de poder precisam ser constantemente negociados em termos políticos e culturais. O conflito é a alternativa a tornar a heterogeneidade um valor central na promoção do convívio, criatividade e capacidade de inovação humana.

GUSTAVO Lins RiBEIRO é professor do Departamento de Antropologia da Universidade de Brasília. 